\title{
Hypoxia-Induced Endothelial Progenitor Cell Function Is Blunted in Angiotensinogen Knockout Mice
}

\author{
Jin-Hwa Choi ${ }^{1,2}$, Minh-Phuong Nguyen ${ }^{1,2}$, Dongjin Lee ${ }^{1,2}$, Goo-Taeg $\mathrm{Oh}^{3}$, and You-Mie Lee ${ }^{1,2, *}$
}

\begin{abstract}
Angiotensinogen (AGT), the precursor of angiotensin I, is known to be involved in tumor angiogenesis and associated with the pathogenesis of coronary atherosclerosis. This study was undertaken to determine the role played by AGT in endothelial progenitor cells (EPCs) in tumor progression and metastasis. It was found that the number of EPC colonies formed by AGT heterozygous knockout $\left(\mathrm{AGT}^{+/}\right.$) cells was less than that formed by wild-type (WT) cells, and that the migration and tube formation abilities of $\mathrm{AGT}^{+/-}$EPCs were significantly lower than those of WT EPCs. In addition, the gene expressions of vascular endothelial growth factor (VEGF), Flk1, angiopoietin (Ang)-1, Ang-2, Tie-2, stromal derived factor (SDF)-1, C-X-C chemokine receptor type 4 (CXCR4), and of endothelial nitric oxide synthase (eNOS) were suppressed in $\mathrm{AGT}^{+/-}$EPCs. Furthermore, the expressions of hypoxia-inducible factor (HIF)-1 $\alpha$ and $-2 \alpha$ were downregulated in $\mathrm{AGT}^{+/-}$early EPCs under hypoxic conditions, suggesting a blunting of response to hypoxia. Moreover, the activation of Akt/eNOS signaling pathways induced by VEGF, epithelial growth factor (EGF), or SDF-1 $\alpha$ were suppressed in $\mathrm{AGT}^{+/-} \mathrm{EPCs}$. In $\mathrm{AGT}^{+/-}$mice, the incorporation of EPCs into the tumor vasculature was significantly reduced, and lung tumor growth and melanoma metastasis were attenuated. In conclusion, AGT is required for hypoxia-induced vasculogenesis.
\end{abstract}

\section{INTRODUCTION}

It has been suggested that blood pressure and angiogenesis are related phenomena, but the molecular link between the two

\footnotetext{
${ }^{1}$ National Basic Research Laboratory of Vascular Homeostasis Regulation, ${ }^{2}$ Research Institute of Pharmaceutical Sciences, College of Pharmacy, Kyungpook National University, Daegu 702-701, Korea, ${ }^{3}$ Department of Life Science, Ewha University, Seoul 120-750, Korea *Correspondence: lym@knu.ac.kr
}

Received 9 May, 2014; revised 3 June, 2014; accepted 5 June, 2014; published online 18 June, 2014

Keywords: angiotensinogen, endothelial progenitor cell, tumor, vasculogenesis, hypertension remains elusive. The renin-angiotensin system (RAS) is a hormone system that regulates blood pressure and water balance (Furuya et al., 2008; Giannotti et al., 2010; Marsboom et al., 2008), and recent studies suggest that components of the RAS are novel candidate angiogenesis regulators (Kaji et al., 2012; Roks et al., 2011). Angiotensinogen (AGT) is the known precursor of angiotensin I, an inactive decapeptide that is further converted by ACE into angiotensin II, the main effector molecule of the RAS (Clapp et al., 2009). AGT is considered to control blood pressure and believed to occur in the renal tubules and tissues (Kobori et al., 2007). Molecular variants of the product of the AGT gene are known to be associated with the pathogeneses of coronary atherosclerosis and severe preeclampsia, the latter of which is the most distinctive and life-threatening form of diseases and characterized by high blood pressure and proteinuria (Ishigami et al., 1995; Ward et al., 1993). No specific AGT receptor has yet been detected, but AGT proteins bind to angiotensin type 1 (AT1) and type 2 (AT2) receptors at micromolar plasma concentrations (Genain et al., 1984).

Endothelial progenitor cells (EPCs) were first isolated from adult peripheral blood in 1997 (Asahara et al., 1997). and possess the abilities of self-renewal in bone marrow (BM), mobilization into the circulatory system in response to stressand/or damage-related signals, recruitment to sites of neovasularization, and commitment and differentiation to mature endothelial cells (ECs) (Asahara et al., 1999; Obi et al., 2009; Urbich and Dimmeler, 2004). In particular, tissue hypoxia is a well-known stimulator of the mobilization of EPCs from BM and of neovasculogenesis (Akita et al., 2003; Youn et al., 2011). However, lack of evidences on true nature and mechanism of action for isolated EPCs extends use of the term to endothelial colony forming cells (ECFCs) or colony forming unit-EC (CFUEC) depending on their current methods of identifying or quantifying the EC lineage potential (Fadini et al., 2012). Besides, BM derived side population cells can develop endothelial cells (Yoon et al., 2008). It is also characterized EPC-CFUs as their hierarchical relationship between primitive small-cell CFUs and definite large-cell CFUs in vitro (Masuda et al., 2011) and we used this refined method in this study as functional EPCs (Kwon et al., 2011). Short-term protocol (4-7 days) can be also used but yield cells with myeloid/hematopoietic characteristics. In particular, "early EPCs" cultured in EC growth media for short-term period (4-7 days) express 
Table 1. Primer sequences for $P C R$

\begin{tabular}{|c|c|c|c|}
\hline Name & & Primer sequence & Application \\
\hline \multirow{2}{*}{ SDF-1 } & Forward & 5'-CTGTAGCCTGACGGACCAAT-3' & real-time qPCR \\
\hline & Reverse & 5'-CCATTCTACAGGAGGCCAAA-3' & \\
\hline \multirow{2}{*}{ CXCR4 } & Forward & 5'-AGCCTCTGCTCATGGAGTTG-3' & real-time qPCR \\
\hline & Reverse & 5'-GCCAAGTTCAAAAGCTCTGC-3' & \\
\hline \multirow{2}{*}{ Ang1 } & Forward & 5'-AACCTCACСCTGCAAAGATG-3' & real-time qPCR \\
\hline & Reverse & 5'-CACAGATGGCCTTGATGTTG-3' & \\
\hline \multirow{2}{*}{ Ang2 } & Forward & 5'-CAAGGCACTGAGAGACAC-3' & real-time $\mathrm{qPCR}$ \\
\hline & Reverse & 5'-TGCGCTTCAGTCTGGTACAC-3' & \\
\hline \multirow{2}{*}{ Tie-2 } & Forward & 5'-GCTTGCTCCTTTCTGGAACTGT-3' & real-time $\mathrm{qPCR}$ \\
\hline & Reverse & 5'-CGCCACCCAGAGGCAAT-3' & \\
\hline \multirow{2}{*}{ VEGF } & Forward & 5'-GGGCAGAGCTGAGTGTTAGC-3' & real-time qPCR \\
\hline & Reverse & 5'-TCTCCCAGATCGGTGACAGT-3' & \\
\hline \multirow{2}{*}{ FLK1 } & Forward & 5'-TTCCCCCCTGGAAATCCT-3' & real-time qPCR \\
\hline & Reverse & 5'-ACAGACCCGGCCAAACAA-3' & \\
\hline \multirow{2}{*}{ eNOS } & Forward & 5'-CGGCATCACCAGGAAGAAGA-3' & real-time qPCR \\
\hline & Reverse & 5'-CATGAGCGAGGCGGAGAT-3' & \\
\hline \multirow{2}{*}{$\beta$-actin } & Forward & 5'-AAGTСССТСАСССТСССАAАAG-3' & real-time qPCR \\
\hline & Reverse & 5'-AAGCAATGCTGTCACCTTCCC-3' & \\
\hline \multirow{2}{*}{ AGT } & Forward & 5'-GTGCCCCTAGGTGAGAGAGC-3' & semi-qPCR \\
\hline & Reverse & 5'-GTGCCTGAGTCCTGCTCGTA-3' & \\
\hline \multirow{2}{*}{ AT1R } & Forward & 5'-TGGCGATTGTGCTTTTCTTC-3' & semi-qPCR \\
\hline & Reverse & 5'-ACAGGCTTGAGTGCGACTTG-3' & \\
\hline \multirow{2}{*}{ AT2R } & Forward & 5'-GGCCTTGGCTGACTTACTCC-3' & semi-qPCR \\
\hline & Reverse & 5'-TACCCATCCAGGTCAGAGCA-3' & \\
\hline \multirow{2}{*}{ GAPDH } & Forward & 5'-CCAGCCTCGTCCCGTAGACA-3' & semi-qPCR \\
\hline & Reverse & 5'-CTGGTCCTCAGTGTAGCCAAGATG-3' & \\
\hline
\end{tabular}

typical EC markers and myeloid/hematopoietic markers, but has functional improvement in ischemic diseases such as myocardial infarction (Hur et al., 2007; Kalka et al., 2000).

Interestingly, clinical evidence demonstrates that EPC level is elevated in a wide variety of cancer tissues (Dome et al., 2006; Igreja et al., 2007; Naik et al., 2008), and EPCs are being viewed as autologous vectors for the delivery of therapeutic cells and genes to sites of vascular growth in both regenerating tissues and tumors (Roncalli et al., 2011). However, it is still unclear that family history for cardiovascular diseases associates with low EPCs. Hypertention have been associated with reduced circulating EPCs (Fadini et al., 2012). Since RAS modulation is a major pharmacotherapeutic strategies for the treatment of cardiovascular diseases, its effects on EPCs are of importance in the context of optimizing RAS interventional or regenerative therapy. Angiotensin converting enzyme 2 (ACE2) priming enhances EPC function in vitro and in vivo using AGT transgenic mice (Chen et al., 2013). However, in contrast to the enormous number of studies conducted on tumor angiogenesis, few have addressed the regulatory role played by AGT in tumor vasculature, especially in hypoxic microenvironment. Using AGT deficient mice (Tanimoto et al., 1994), we analyzed function or nature of EPCs in response to hypoxia and suggested the possible relationship between innate low blood pressure and decreased EPCs function. In the present study, we cultured mouse BM-derived EPCs and examined the effects of AGT haplo-insufficiency on their proliferation, differentiation, and migration. In addition, we investigated the effects of AGT on tumor growth and metastasis, on EPC mobilization from BM to the peripheral circulation, and on the incorporation of EPCs into tumor vessels using a mouse tumor model using BM transplantation method.

\section{MATERIALS AND METHODS}

Mice

Animal experiments were performed using C57BL/6J mice (SLC, Japan), which were handled in strict compliance with the guidelines for care and use of laboratory animals issued by the institutional ethical animal care committee of Kyungpook National University Animal Care and Use Committee (Approved number: KNU2012-51, Korea) according to the guidelines from $\mathrm{NIH}$ guidelines (Guide for the care and use of laboratory animals). Mice were maintained under specific pathogen-free conditions and treated with $\mathrm{CO}_{2}$ by inhalation in chamber for anesthesia just before sacrifice. Transgenic mice expressing green fluorescent protein (GFP) under chick $\beta$-actin promoter (C57BL/ $6 \mathrm{~J}$ ) and $\mathrm{AGT}^{+/}$mice generated as previously reported (Kim et al., 1995). 
Isolation of mononuclear cells from mouse bone marrow and peripheral blood

Mice were treated with $\mathrm{CO}_{2}$ by inhalation for anesthesia and all long bones were isolated from the mice. Mononuclear cells (MNCs) were isolated from WT or $\mathrm{AGT}^{+/-}$mouse bone marrow (BM) or peripheral blood (PB) using a Histopaque-1083 density gradient based method (Sigma, USA). Freshly isolated MNCs were resuspended in EGM-2 media (Lonza, Switzerland) supplemented with $5 \%$ fetal bovine serum (FBS, Hyclone, USA), basic fibroblast growth factor (bFGF), VEGF, insulin-like growth factor-1 (IGF-1), epidermal growth factor (EGF), ascorbic acid and heparin, and seeded onto $60 \mathrm{~mm}$ dishes $\left(2 \times 10^{7}\right.$ cells/ dish). After culture for 4 days, nonadherent cells were removed by washing with PBS and attached cells in gelatin-coated dishes were further cultured for 3 days. These cells were 'early EPCs' (Hur et al., 2007; Kalka et al., 2000).

EPC colony forming assay (EPC-CFA) (Masuda et al., 2011) After isolation of $\mathrm{c}-\mathrm{kit}^{+} / \mathrm{Sca}-1^{-/} / \mathrm{Lin}^{-}$(KSL) cells from mouse BM (Kwon et al., 2011), the frequencies of small or large colonies was determined after culturing KSL cells (500 cells/35 mm dish) for 10 days in methylcellulose-containing medium M3236 (Stem Cell Technologies) supplemented with $20 \mathrm{ng} / \mathrm{ml}$ stem cell factor (SCF), $50 \mathrm{ng} / \mathrm{ml}$ VEGF, $20 \mathrm{ng} / \mathrm{ml}$ interleukin-3 (IL-3) (R\&D Systems), 50 ng/ml bFGF, 50 ng/ml EGF (PeproTech), 2 U/ml heparin (Sigma), 30\% FBS, and antibiotics. Colony forming units (CFUs) were counted under an inverted microscope at 40x. In our previous study, we defined small- and large-CFUs for the expression of additional endothelial marker genes such as CD31, Flk-1, von Willebrand factor (vWF), VE-cadherin and eNOS (Kwon et al., 2011).

Early EPC migration assay

A polycarbonate filter (8- $\mu \mathrm{m}$ pore size) was placed between the upper and lower chambers of a transwell unit. Cell suspensions $\left(5 \times 10^{4}\right.$ cells) were placed in the upper chamber, and the lower chamber was filled with EGM-2 basal medium containing VEGF, EGF or murine recombinant stromal-derived factor-1 $\alpha$ (SDF$1 \alpha$; PeproTech) and incubated for $6 \mathrm{~h}$. Migrated cells on the lower side of filters were fixed with methanol, stained with hematoxylin and eosin (Sigma), and counted in five randomly selected microscopic fields (200x).

\section{Tube formation assay}

Human umbilical vein endothelial cells (HUVECs) (BD Biosciences) were mixed with 'early EPCs' $\left(10^{4}\right.$ HUVECs and $10^{3}$ early EPCs in $100 \mu$ l of $5 \%$ FBS/EGM-2) and seeded on a 96well culture plate coated with Matrigel (BD Biosciences) for 30 $\min$ at $37^{\circ} \mathrm{C}$. Plates were examined for tube formation after incubation for $8 \mathrm{~h}$. Numbers of tubular formations were counted at $200 x$.

RNA isolation and real-time and semi-quantitative PCR Total RNA was extracted from mouse 'early EPCs' using Trizol (Invitrogen) according to the manufacturer's instructions. For real time-RT-qPCR, cDNA synthesis was performed using 0.5 $\mu \mathrm{g}$ of total RNA and an ExScript RT reagent Kit (TaKaRa, Japan). Real-time PCR was performed using a SYBR Green PCR Master Mix (Applied Biosystems) and gene-specific primers shown in Table 1 . The thermal cycle used was 2 min at $50^{\circ} \mathrm{C}, 10 \mathrm{~min}$ at $95^{\circ} \mathrm{C}, 40$ cycles of $15 \mathrm{~s}$ denaturation at $95^{\circ} \mathrm{C}$, and $1 \mathrm{~min}$ annealing at $60^{\circ} \mathrm{C}$. Relative gene expressions were calculated from mean cycle threshold $(\mathrm{Ct})$ values with respect to $\beta$-actin (internal control).
For semi-quantitative RT-PCR, cDNA synthesis was performed using $2 \mu \mathrm{g}$ of total RNA using M-MLV reverse transcriptase (Promega, USA). A cDNA sample $(1 \mu \mathrm{l})$ was subjected to PCR amplification using gene-specific primers and Diaster Taq DNA polymerase (Solgent, Korea). Table 1 summarizes the sequences of the primers used in this study.

Western blot analysis

Western blot analysis was performed as previously described (Jung et al., 2012).

\section{Flow cytometric analysis}

To determine circulating EPC numbers, MNCs isolated from peripheral blood (PB) were stained with FITC-conjugated antiCD34 monoclonal antibody (GeneTex, Inc., USA) and PEconjugated anti-VEGFR2 monoclonal antibody (BD Biosciences). 'Early EPCs' were stained with FITC-conjugated anti-CD14 (BD Pharmingen) or AlexaFluor ${ }^{\circledR}$ 647- anti-CD45.2 antibody (BioLegend). A FACScalibur unit (BD Biosciences) was used to detect fluorescent labeled cells.

Bone marrow transplantation (BMT) and tumor xenograft model

C57BL/6 wild type (WT) mice or $\mathrm{AGT}^{+/}$mice were exposed to a lethal dose of total body irradiation (10 Gy), and injected intravenously with $10^{7}$ BM-derived MNCs collected from GFPexpressing C57BL/6 or $\mathrm{AGT}^{+/}$mice. Mice were inoculated subcutaneously in the flank with $10^{6}$ Lewis lung carcinoma cells (LLC) or B16F10 melanoma cells at 4 weeks post-injection, and tumor bearing mice were sacrificed 2 weeks later.

Immunohistochemistry (IHC) and Immunofluorescence Tumor masses or 'early EPCs' were fixed with $4 \%$ paraformaldehyde (PFA) in PBS. Sections were prepared from OCT embedded tumor tissues and washed in PBS. After blocking with $1 \%$ bovine serum albumin (BSA, Sigma) in PBS, sections were stained with rat anti-mouse CD31 antibody overnight at $4^{\circ} \mathrm{C}$, and then with Alexa Flour 647 -conjugated anti-rat antibody (Invitrogen). Fixed cells were stained with FITC-conjugated anti-CD34 monoclonal antibody (GeneTex) and PE-conjugated anti-VEGFR2 monoclonal antibody (BD Biosciences).

\section{Statistics}

SPSS version I was used for the statistical analyses. ANOVA was used to compare the experimental groups. Statistical significance was accepted for $p$ values $<0.05$, and results are presented as means \pm standard deviations (SD).

\section{RESULTS}

Characterization of 'early EPCs'

After 7 days in culture, attached MNC cells changed from a round to a spindle-shaped morphology but did not form colonies yet during culture in the presence of endothelial cell (EC) growth supplements. These cells were characterized by the uptake of Dil-Ac-LDL and isolectin B4 binding $(96.1 \pm 1.51 \%$ of attached cells) (Fig. 1A). Immunofluorescent staining further demonstrated the expression of CD34 (a HSC marker) and of VEGFR2 (Flk1, an EC marker). The percentage of CD34 and VEGFR2 double positive cells among attached cells was $90.0 \pm$ $3.8 \%$ (Fig. 1A). Therefore, we further used these cells as 'early EPCs' (Hur et al., 2007; Kalka et al., 2000). 
A

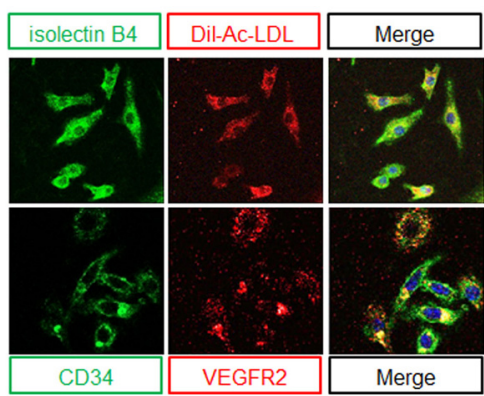

C

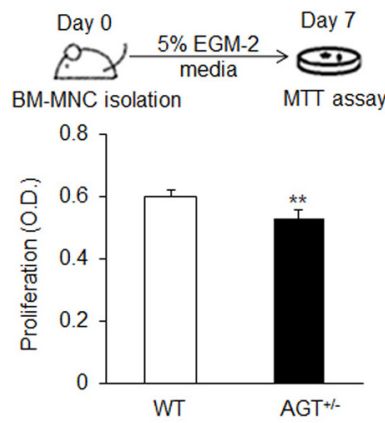

B

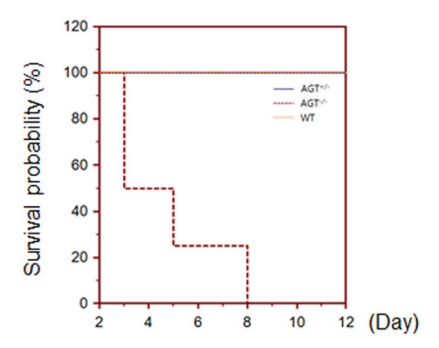

D

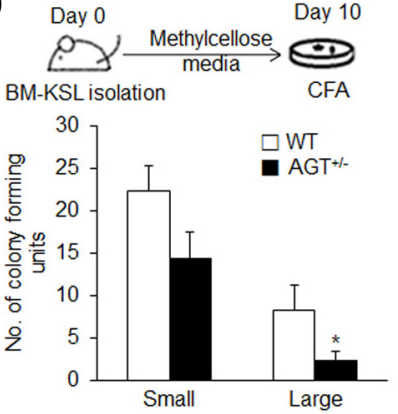

B

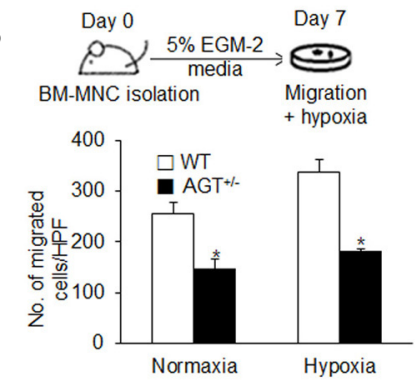

D

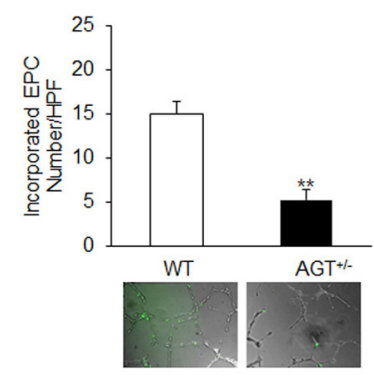

Fig. 1. Characterization of early EPCs isolated from WT and AGT knockout mice. (A) MNCs were isolated from mouse BM and cultured for 7 days. Immunofluorescent staining of these cultured cells with isolectin B4, Dil-Ac-LDL, CD34, and VEGFR2. (B) Survival rates of WT mice, $\mathrm{AGT}^{+/-}$mice and $\mathrm{AGT}^{-1}$ mice as determined by Kaplan-Meier survival curve analysis. (C) Schematic representation of the MTT assay. MNCs were isolated from mouse BM and cultured for 7 days (upper panel). Cell proliferation was determined using an MTT assay (lower panel). (D) Schematic representation of CFA. $\mathrm{KSL}$ cells were isolated from mouse BM, and seeded in methylcellulose containing media for 10 days (upper panel). Small-CFUs and largeCFUs were defined as round-shaped small cells and spindle-shaped large cells, respectively. Number of colonies formed by KSL cells were counted (lower panel). Three independent experiments were performed in all experiment. ${ }^{* *}$ Statistical significance $(p<0.01)$.

Fig. 2. Angiogenic potential of $A G T^{+/}$EPCs is decreased in vitro. (A) Schematic representation of the migration assay (upper panel). The migration assay was performed using EGM-2 basal media containing VEGF $(10 \mathrm{ng} / \mathrm{ml})$, EGF $(50 \mathrm{ng} / \mathrm{ml})$, or SDF-1 $\alpha(100 \mathrm{ng} / \mathrm{ml})$, which served as chemoattractants. EPCs starved for $24 \mathrm{~h}$ were plated onto 24-well transwell membranes. After $6 \mathrm{~h}$, cells that had migrated onto the bottom face of membranes were counted. (B) Schematic representation of the migration assay under normoxic and hypoxic conditions (upper panel). Cell numbers that migrated under the hypoxic condition were counted (lower panel). (C) Schematic representation of the tube formation assay (upper panel). GFP expressing EPCs were co-cultured with HUVECs on Matrigel matrix for $8 \mathrm{~h}$. Capillary networks were visualized under a fluorescence microscope (x 200). The graphs show numbers of branch points (lower panel). (D) Representative photomicrographs of tube formation by HUVECs and EPCs (upper panel). The graphs represent numbers of incorporated GFP-EPCs (lower panel). Three independent experiments were performed in triplicate. *Statistical significance $(p<0.05)$ ${ }^{* *}$ Statistical significance $(p<0.01)$.
The proliferation and differentiation of EPCs were suppressed in $\mathrm{AGT}^{+/-}$mice

An EPC-colony forming assay (EPC-CFA) was used to investigate the proliferation and differentiation of EPCs lacking AGT. Haplo-insufficient AGT knockout cells from $A_{G} T^{+/-}$mice were used in this experiment because $\mathrm{AGT}^{-1-}$ mice died within 8 days of birth (Fig. 1B). In this assay, KSL cells give rise to functional EPC progeny, which are identified as two types of EPCs for differentiation cascade in terms of physiological model of an EPC hierarchy (Masuda et al., 2011). EPC-colonies composed of relatively small and round cells (called small-CFUs) indicate the characteristics of primitive EPC, such as, a high proliferative phenotype and the preservation of immature properties. Whereas large-CFUs composed of spindle-shaped cells indicate late or mature EPC characteristics, including rapid tube formation ability and improved neovascularization (Kwon et al., 2011). In fact, we already characterized these CFUs for the expression of additional EC marker genes, such as VEGFR2, VE-cadherin, vWF, CD31, Ac-LDL/isolectin B4 and eNOS, suggesting that these CFUs are functional EPCs (Kwon et al., 2011). 
A
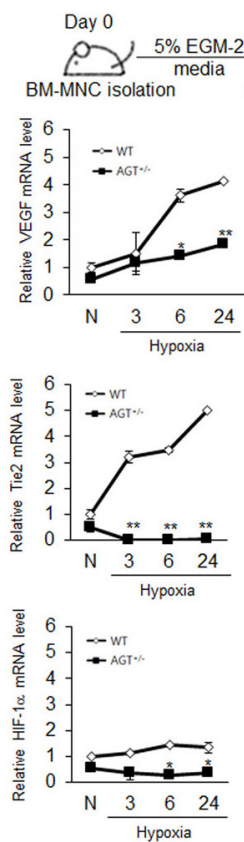

Day 7

$\rightarrow$ mRNA isolation
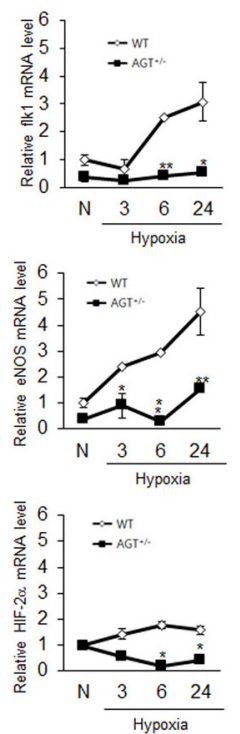
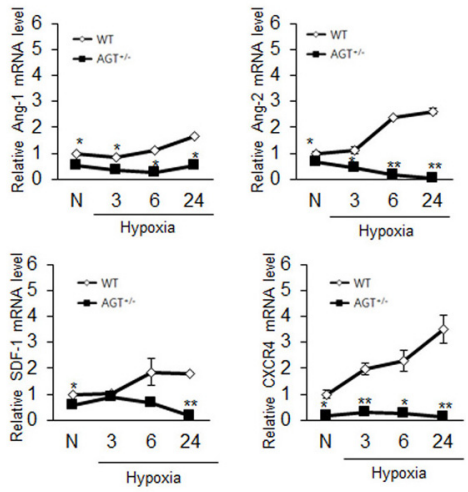

B

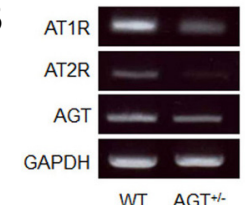

Fig. 3. Expression of growth factors, receptors involved in vasculogenic function of EPCs is blunted in AGT-knockout early EPCs under hypoxic conditions. Total RNA was extracted from cultured early EPCs. (A) Real-time RTqPCR was performed using SYBR green. To evaluate target gene expressions, mean $\mathrm{Ct}$ values were used to calculate gene expressions, which were normalized with respect to $\beta$ actin. Data are the means \pm SDs of three independent experiments. (B) Detection of AT1R and AT2R mRNA by RT-PCR. GAPDH served as an internal control. Three independent experiments were performed in all experiment. *Statistical significance $(p<0.05)$, ${ }^{* *}$ Statistical significance $(p<0.01)$.
As shown in Fig. 1C, the growth rate of $\mathrm{AGT}^{+/}$EPCs was lower than that of the WT, and the number of large CFUs was reduced, indicating that the differentiation capacity of $\mathrm{AGT}^{+/-}$ EPCs was lower than that of WT EPCs (Fig. 1D).

Inhibition of early EPC migration induced by growth factors or hypoxic conditions in $\mathrm{AGT}^{+/-}$early EPCs

To investigate the role of AGT in the migration ability of EPCs, migration assays were performed on WT and $\mathrm{AGT}^{+/-}$"early EPCs'. Growth factors, such as, VEGF, EGF, and SDF-1 $\alpha$ play important roles in the regulation of a variety of cellular functions of EPCs, including cell migration, proliferation, and survival (Aghila Rani and Kartha, 2010; Asahara et al., 1999; Fu et al., 2007). As shown in Fig. 2A, in the presence of VEGF $(10 \mathrm{ng} / \mathrm{ml})$, EGF $(50 \mathrm{ng} / \mathrm{ml})$, or SDF-1 $\alpha(100 \mathrm{ng} / \mathrm{ml})$, WT early EPCs migrated efficiently through the membrane. However, the growth factor-induced migrations of $\mathrm{AGT}^{+/-}$early EPCs were obviously diminished (Fig. 2A). Furthermore, hypoxia-induced migration was inhibited in $\mathrm{AGT}^{+/}$EPCs as compared with WT EPCs (Fig. 2B).

\section{Suppression of tube formation by $\mathrm{AGT}^{+/-}$EPCs co-cultured with HUVECs}

To investigate the tube forming abilities of early EPCs, we used an in vitro assay of capillary tube formation on Matrigel matrix. WT or $\mathrm{AGT}^{+-}$early EPCs were co-cultured with HUVECs for 8 $\mathrm{h}$ on Matrigel matrix. Figure $2 \mathrm{C}$ shows capillary formation by HUVECs and early EPCs. The number of incorporated $\mathrm{AGT}^{+/-}$ EPCs into branches was markedly lower than that of WT early EPCs (Fig. 2D). Moreover, the number of GFP-expressing EPCs in tubes was lower for $\mathrm{AGT}^{+/-}$EPCs than for WT EPCs, implying that AGT depletion substantially reduced the contribution of EPCs to tubular networks.

Blunted expressions of hypoxia-induced factors or receptors in $\mathrm{AGT}^{+/-}$early EPCs

To investigate the expression levels of various cytokines and receptors in EPCs from mouse BM, real-time qPCR was used to measure their mRNA levels in WT or $\mathrm{AGT}^{+/-}$early EPCs cultured under hypoxic conditions. The results obtained revealed that AGT deletion attenuated the expressions of vasculogenesis-associated genes (Fig. 3). In hypoxia, WT early EPCs exhibit time-dependent elevated expressions of EPC-promoting factors and their receptors, such as, of VEGF, Flk1, SDF-1, CXCR4, angiopoietin-1 (Ang-1), Ang-2, Tie-2, and eNOS mRNA. However, hypoxic conditions did not increase these mRNA levels in $\mathrm{AGT}^{+-}$early EPCs compared to WT. In addition, HIF- $1 \alpha$ and HIF- $2 \alpha$ mRNA levels were measured under hypoxic conditions, and both were found to be reduced in $\mathrm{AGT}^{+/-}$early EPCs compared to that of WT (Fig. 3A). Furthermore, the mRNA levels of AT1R and AT2R (receptors for AGT) were less in $\mathrm{AGT}^{+-}$early EPCs than in WT early EPCs (Fig. 3B). These results indicate that function of $A G T^{+/}$early EPCs is inhibited by the down-regulations of EPC-promoting factors and their receptor-mediated signaling under hypoxic conditions.

Suppression of growth factor-induced signaling pathways in $\mathrm{AGT}^{+/-}$early EPCs

The Akt/eNOS and MAPK signaling pathways control the migration, proliferation, survival, and differentiation of EPCs (Fu et al., 2007). Accordingly, we examined whether the growth factorinduced activation of these signaling pathways is responsible for the reduced EPC activity in $\mathrm{AGT}^{+/-}$mice. As shown in Fig. $4 \mathrm{~A}$, stimulation with VEGF, SDF-1 $\alpha$, or EGF strongly activated Akt, Erk, and eNOS in WT early EPCs but not $\mathrm{AGT}^{+-}$early EPCs.

Because VEGF is a key regulator of vasculogenesis (Asahara et al., 1999), we also measured the protein levels of VEGF and its receptor in WT and $A_{G T^{+/-}}$early EPCs. VEGF and Flk1 levels were clearly lower in $\mathrm{AGT}^{+/-}$early EPCs, but Flt1 expression was higher, suggesting that VEGF signaling via Flk1 (VEGFR2) is inhibited in $\mathrm{AGT}^{+/-}$early EPCs (Fig. 4B). In addition, we measured the protein levels of HIF-1 $\alpha$ and integrin-linked kinase (ILK), which are important regulators of EPC function 
A

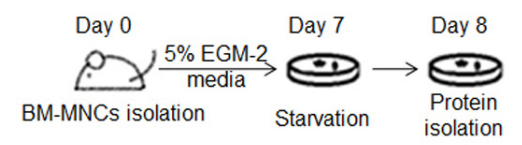

B

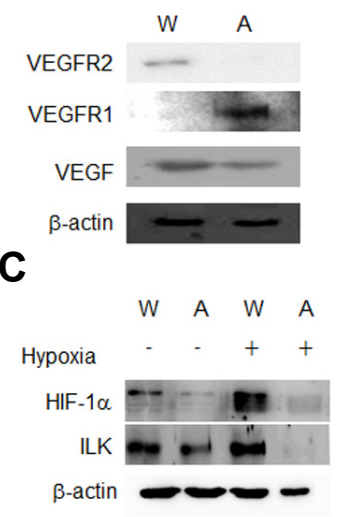

A

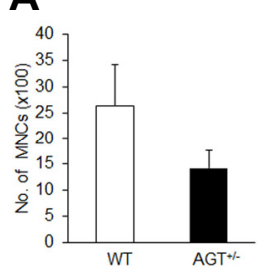

B

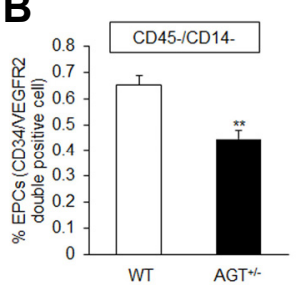

C

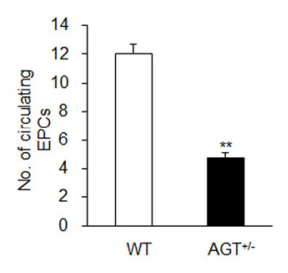

Fig. 4. VEGF- or SDF-1 $\alpha$-induced signaling pathways are blocked in $\mathrm{AGT}^{+/}$EPCs. (A) After $24 \mathrm{~h}$ of starvation, WT EPCs or $\mathrm{AGT}^{+/-}$EPCs were stimulated with $10 \mathrm{ng} / \mathrm{ml}$ VEGF, $50 \mathrm{ng} / \mathrm{ml} \mathrm{EGF}$, or $100 \mathrm{ng} / \mathrm{ml} \mathrm{SDF}-1 \alpha$ for $10 \mathrm{~min}$. Levels of phosphorylated eNOS, eNOS, phosphorylated Akt, Akt, phosphorylated Erk, Erk or $\beta$-actin were determined with appropriate antibodies by immunoblotting. (B) After 7 days of culture, proteins were isolated from both WT and $\mathrm{AGT}^{+/-}$early EPCs. Level of VEGFR1, 2 or $\beta$-actin were determined with appropriate antibodies by immunoblotting. (C) After $4 \mathrm{~h}$ under hypoxic conditions, proteins were isolated from early EPCs. Expression of HIF- $1 \alpha$, ILK or $\beta$-actin was determined with appropriate antibodies by immunoblotting. Three independent experiments were performed in all experiment.

Fig. 5. Mobilization of EPCs from BM to the peripheral circulation is attenuated in $\mathrm{AGT}^{+/}$mice. MNCs were isolated from peripheral blood $(P B)(n=3)$ and stained with a FITCconjugated anti-CD34 and PE-conjugated anti-VEGFR2 antibodies. Flow cytometric analysis was used to detect CD34+ VEGFR2+ cells in the circulating MNC population. (A) The number of MNCs in PB. (B) Ratio of CD34/NEGFR2 double positive cells in CD45-/CD14- cells (C) Total number of circulating EPCs in PB. Three independent experiment were performed in all experiment. ${ }^{*}$ Statistical significance $(p<0.01)$. under hypoxic conditions (Lee et al., 2006). We found HIF-1 $\alpha$ and ILK levels were far lower in $\mathrm{AGT}^{+/-}$early EPCs than in WT early EPCs both under normoxic and hypoxic conditions (Fig. 4C).

Reduced mobilization of EPCs from the BM to the peripheral circulation in $\mathrm{AGT}^{+/-}$mice

Numbers of circulating EPCs in WT and $\mathrm{AGT}^{+/-}$mice were also investigated. MNCs were isolated from the peripheral blood (PB) of WT or $\mathrm{AGT}^{+-}$mice and the expressions of the EPC markers CD34 and VEGFR2 were detected by flow cytometry. But myeloid markers, CD11+/ CD45+ cells were removed. As shown in Fig. 5A, MNC numbers were lower in $\mathrm{AGT}^{+/}$mice $(1418.9 \pm 346.47$ cells per $1 \mu \mathrm{lPB})$ than in WT mice $(2634.8 \pm$ 789.09 cells per $1 \mu \mathrm{lPB}$ ). The proportion of EPCs among PBMNCs from $\mathrm{AGT}^{+/-}$mice $(0.44 \% \pm 0.032 \%)$ was also smaller than for WT mice $(0.65 \% \pm 0.035 \%)$ (Fig. 5B). Taken together, circulating EPCs counts in $1 \mu \mathrm{l}$ of PB from $\mathrm{AGT}^{+/}$mice $(4.76 \pm$ $0.35)$ were lower than those of WT mice $(12.03 \pm 0.64)$ (Fig. $5 \mathrm{C})$.

Xenograft tumor growth and metastasis were reduced in $\mathrm{AGT}^{+/-}$mice

The effect of AGT deletion on the incorporation of EPCs into tumor neovessels was investigated by cross BM transplantation,

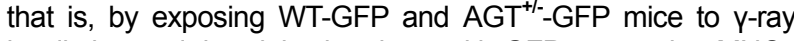
irradiation and then injecting them with GFP-expressing MNCs isolated from $\mathrm{AGT}^{+/-}$-GFP or WT-GFP mice, respectively, and inoculating with lung cancer cells (LLCs) into BM transplanted mice. In WT mice injected with WT MNCs, rapid tumor growth was observed, however in AGT haploinsufficient mice as donors, receivers, or both, tumor growth was significantly inhibited
(Fig. 6A).

To investigate metastasis, we inoculated B16F10 cells into a tail vein in WT or $\mathrm{AGT}^{+/-}$mice, and 10 days later counted numbers of lung nodules. As shown in Fig. 6B, the number of metastatic nodules in $\mathrm{AGT}^{+-}$mice $(72.0 \pm 5.66)$ was significantly lower than in WT mice $(219.5 \pm 3.54)$. These results indicate that tumor growth and metastasis were suppressed in $\mathrm{AGT}^{+/-}$ mice.

Inhibition of the incorporation of EPCs into tumor neovessels in $\mathrm{AGT}^{+/-}$mice

To assess the contribution of BM-derived EPCs to LLC tumor growth, we stained tumor tissues with CD31 (an endothelial cell marker). Marked recruitment of BM-derived GFP+ cells expressing CD31 (Fig. 6C) was observed in WT mice transplanted with WT BM-MNCs and in $\mathrm{AGT}^{+/-}$mice transplanted with WT BM-MNCs, but not in WT mice transplanted with $A G T^{+/-} B M-$ MNCs or $\mathrm{AGT}^{+/-}$mice transplanted with $\mathrm{AGT}^{+/-} \mathrm{BM}-\mathrm{MNCs}$ (Fig. 6D). Thus, GFP ${ }^{+} \mathrm{CD} 31^{+}$cells were clearly diminished in WT mice transplanted with $\mathrm{AGT}^{+/} \mathrm{BM}-\mathrm{MNCs}$ and in $\mathrm{AGT}^{+/-}$mice transplanted with $\mathrm{AGT}^{+/-} \mathrm{BM}-\mathrm{MNCs}$ (Fig. 6E). These results suggest that AGT attenuation limits tumor progression by inhibiting the incorporation of EPCs into neovessels.

\section{DISCUSSION}

In the present study, we focused on the in vitro and in vivo functions of $\mathrm{AGT}^{+/}$EPCs to determine the role played by AGT in EPCs during vasculogenesis. The results obtained during the course of the study suggest that AGT is importantly required for the participation of EPCs in tumor neovascularization and metastasis. Initially we found that the number of large EPC-CFUs 
A

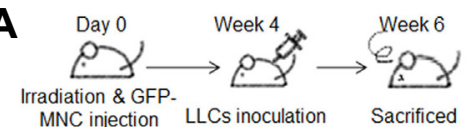

MNC injection LLCs inoculation Sacrificed

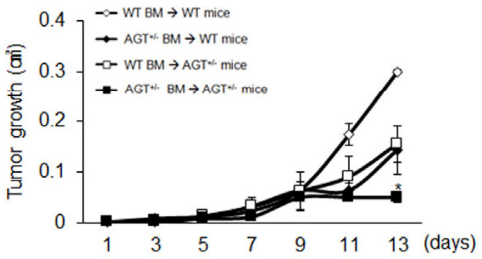

C

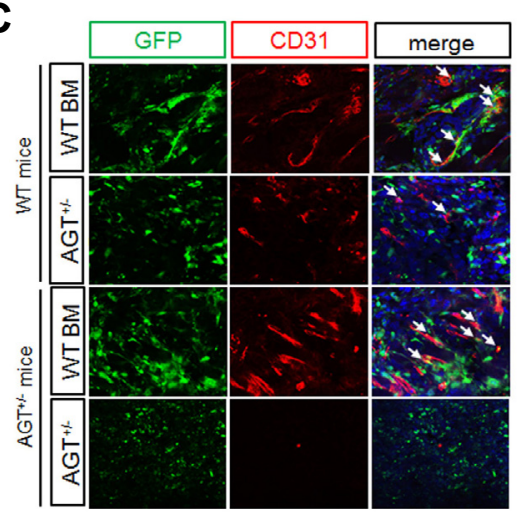

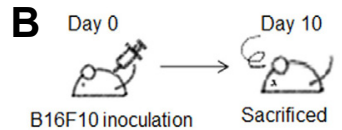

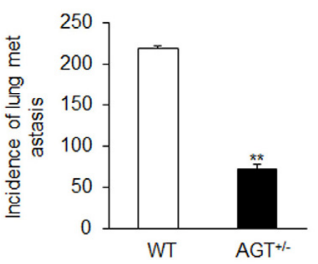

D

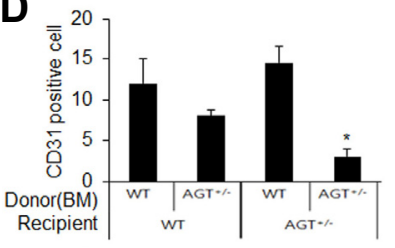

E

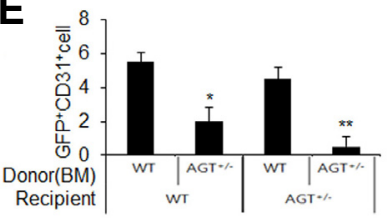

Fig. 6. EPC homing into metastatic or solid tumor vasculature is inhibited in $\mathrm{AGT}^{+/-}$mice. (A) WT or $\mathrm{AGT}^{+/-}$mice $(\mathrm{n}=5)$ were irradiated at $10 \mathrm{~Gy}$ and then injected intravenously with GFP expressing MNCs ( $1 \times 10^{7}$ cells per mouse). One month later, mice were inoculated subcutaneously with $1 \times 10^{5}$ LLC cells; tumor sizes were measured on alternate days. (B) WT or $\mathrm{AGT}^{+/-}$mice $(\mathrm{n}=5)$ were injected with $10^{6}$ B16F10 cells intravenously. After 10 days, mice were sacrificed and lung tumor nodules were counted. (C) Tumor neovascularization in BMT mice. Tumor sections were stained for CD31 (red). The arrows indicate GFP/CD31 double positive cell. (D, E) Quantitative analysis of CD31-positive cells (D) and incorporated EPCs (E) in tissue sections retrieved from tumors. Three independent experiments were performed in all experiment. ${ }^{* *}$ Statistical significance $(p<0.01)$. produced from the BM-derived $\mathrm{KSL}$ cells of $\mathrm{AGT}^{+/-}$mice was reduced (Fig. 1D). Because it has been shown that round- and spindle-shaped EPC-CFUs express EC markers (Kwon et al., 2011) whereas spindle shaped late EPC-CFUs exhibit a greater ability to form functional vessels in ischemia (Masuda et al., 2011), these results indicate that the ability of $\mathrm{AGT}^{+/}$EPCs to differentiate into functional ECs was reduced. Next, we investigated the EPC ability to migrate and form tubes as a means of measuring angiogenic potential in vitro. We found the growth factor- and hypoxia-induced migration activities of $\mathrm{AGT}^{++-}$early EPCs were less than those of WT early EPCs (Figs. 2A and 2B). Tube formation by $\mathrm{AGT}^{+/-}$early EPCs was also less than for WT early EPCs (Fig. 2D). These results indicate that the angiogenic potential of $\mathrm{AGT}^{+/-} \mathrm{EPCs}$ in vitro is smaller than that of WT EPCs. Furthermore, tumor growth was slower in $\mathrm{AGT}^{+/-}$ mice, and the mobilization of EPCs from BM into PB (Figs. 5B and $5 \mathrm{C}$ ) and the incorporation of circulating EPCs into new tumor vessels (Fig. 6) were inhibited in $\mathrm{AGT}^{+/-}$mice.

HIF-1 is the master transcription factor of adaptive response to hypoxia. The primary mechanism of hypoxia-induced angiogenesis involves the upregulation of HIF-1 protein, which results in subsequent upregulations of growth factors and receptors, such as, VEGF, SDF-1, CXCR4, and other (Shweiki et al., 1992; Wu et al., 2003; Youn et al., 2011). It is well known that VEGF and SDF-1 promote neovascularization, and that they facilitate paracrine and hormone-like effects ( $\mathrm{Li}$ et al., 2006; Youn et al., 2011). The immediate effect of VEGF on EPC mobilization is probably related to the prompt development of a chemoattractive gradient and enhanced EPC differentiation ( $\mathrm{Li}$ et al., 2006). Moreover, when acting in concert with VEGF, Ang2 facilitates endothelial cell migration and proliferation, and thus, serves as a permissive angiogenic signal (Mandriota and Pepper, 1998). In a previous study, the up-regulation of VEGF receptor 2 (Flk1) was found to significantly enhance the migration of and tube formation by EPCs via a process dependent on integrin $\alpha_{6}$ subunit (Smadja et al., 2007). EPC mobilization and recruitment substantially depend on the ischemia-induced upregulation of SDF-1 $\alpha$ in tissues (Ceradini et al., 2004), and therefore, the SDF-1/CXCR4 signaling pathway plays an important role during EPC migration, proliferation, survival, and angiogenesis (Fu et al., 2007) in response to hypoxia. Furthermore, recent in vitro studies have shown that Ang II from AGT induces VEGF via AT1R signaling (Anandanadesan et al., 2008), suggesting lower levels of AGT in knockout mice reduce angiotensin II, and that this in turn contributes to reduced VEGF induction. Our results also indicate that decreased levels of HIF-1 in $\mathrm{AGT}^{+/}$EPCs could lead to low VEGF and SDF-1 expression, and thus, reduced expressions of VEGF, Flk1, SDF-1 and CXCR4 might contribute to the suppression of vasculogenesis by $\mathrm{AGT}^{++}$EPCs under hypoxic conditions.

Previous studies have indicated that eNOS is critical for EPC function (Murohara et al., 1998). Indeed, angiogenesis in mouse ischemic hindlimbs was impaired in eNOS-deficient animals and capillary growth was stimulated in a rabbit administered with a NO donor (Murohara et al., 1998). In a previous study, it was observed that increased NO levels in BM resulted in the differentiation and mobilization of EPCs from BM niches to the circulation, and ultimately resulted in their participation in tissue-level vasculogenesis and wound healing (Aicher et al., 2003). The activation of growth factors is mediated by eNOS and the subsequent production of NO, as previously described in ischemia-induced angiogenesis (Fu et al., 2007; Silvestre et al., 2002), which suggests neovascularization or endothelization by $\mathrm{AGT}^{+/-}$EPCs in the present study was inhibited in part by reduced eNOS activation. Because $\mathrm{AGT}^{+/-}$mice have low plasma angiotensin II levels and are hypotensive (Babic et al., 1998), it is interesting that eNOS has an inhibitory effect on hypertension. In man, NO induced by vascular endothelium 
regulates vasodilator tone, and thus, blood pressure (Vallance et al., 1989). In a study of mice lacking the eNOS gene, it was found eNOS function is required for vascular and hemodynamic responses to acetylcholine, and thus, that disruption of eNOS gene leads to hypertension (Huang et al., 1995). Furthermore, recent reports demonstrate that whole-body NO production in patients with essential hypertension is reduced under basal conditions, as determined by measuring urinary and plasma nitrate levels (Forte et al., 1997). This is a systemic effect of NO on the regulation of blood pressure, and thus, the role of AGT on the synthesis and activation of eNOS in EPCs could be a different issue, for example, it might be a local effect on vasculogenesis in ischemic tissues.

The present study shows that expression levels of Ang-1, Ang-2, and Tie-2 were lower in $\mathrm{AGT}^{+-}$EPCs than in WT EPCs. When Tie-2 interacted with Ang-2, angiogenic sprouting was increased in vessels (Fiedler and Augustin, 2006), whereas binding between Tie-2 and Ang-1 matured pre-existing vessels (Lee et al., 2009). The expressions of adhesion molecules were elevated in BM-derived progenitor cells primed with Ang-1, and these cells committed to endothelial lineage and improved engraftment into ischemic tissue and vasculogenesis (Kim et al., 2009). These findings suggest that the inhibition of Ang-1/Tie-2 and Ang-2/Tie-2 signaling due to reductions in the mRNA expressions of Ang-1, Ang-2, and Tie-2 suppresses functions of $\mathrm{AGT}^{+/}$EPCs (Fig. 4).

Tumors are a cause of hypertension (Mendez et al., 2011; Pereira et al., 2004; Ziaja et al., 2008), but relationships between blood pressure and some cytokines related to tumor growth remains controversial. It was reported inhibition of the VEGF signaling pathway induced hypertension in patient with VEGF-targeted therapy (Robinson et al., 2010). On the other hand, in another study, a specific inhibitor of SDF-1/CXCR4 signaling reduced hypoxia-induced pulmonary hypertension and vascular remodeling by decreasing BM-derived cell lung recruitment in chronic hypoxia in rat (Chen et al., 2000), which suggests that a reduction in hypoxia-induced SDF-1/CXCR4 in AGT deficient mice reduces local blood pressure. Furthermore, plasma Ang-2 concentrations were found to be elevated in hypertensive patients, particularly in those with atherosclerosis (David et al., 2009). Unlike Ang-2, the Tie-2/Ang-1 pathway prevented pulmonary arterial hypertension in mice (Kugathasan et al., 2009). Because hypertensive phenotypes are represented from complicated responses of a variety of tissues, such as, heart, microvessels in muscles, and kidneys, our results suggest that one of genes involved in blood pressure homeostasis regulates vascularity via BM-derived EPCs. Our findings are supported by other previous reports regarding RAS system and angiogenesis that angiotensin 1-7 improves endothelial function (Rentzsch et al., 2008), ameliorate angiotensin II-induced EC apoptosis (Yang et al., 2012) and EPCs function is increased by the introducing ACE2 genes in BM-derived EPCs (Chen et al., 2013).

In summary, the present study shows that AGT deficiency attenuates vasculogenesis and EPC function. This inhibitory effect observed in $\mathrm{AGT}^{+/}$EPCs was attributed to a reduction in the differentiation and mobilization of EPCs from BM to hypoxic tissues and to a reduction in EPC function. Furthermore, because HIF-1 levels were reduced in $\mathrm{AGT}^{+/}$EPCs, growth factors were down-regulated and the VEGF/Flk1, SDF-1/CXCR4, and the Tie-2 pathways were inhibited. Additional studies are required to elucidate the mechanism of $\mathrm{HIF}-1$ regulation in AGT+/- EPCs completely.

\section{ACKNOWLEDGMENTS}

This work was supported by a National Research Foundation (NRF) grant funded by the Korean government (MSIP) (2012R1A4A1028835).

\section{REFERENCES}

Aghila Rani, K.G., and Kartha, C.C. (2010). Effects of epidermal growth factor on proliferation and migration of cardiospherederived cells expanded from adult human heart. Growth Factors 28, 157-165.

Aicher, A., Heeschen, C., Mildner-Rihm, C., Urbich, C., Ihling, C., Technau-lhling, K., Zeiher, A.M., and Dimmeler, S. (2003) Essential role of endothelial nitric oxide synthase for mobilization of stem and progenitor cells. Nat. Med. 9, 1370-1376.

Akita, T., Murohara, T., Ikeda, H., Sasaki, K., Shimada, T., Egami, K. and Imaizumi, T. (2003). Hypoxic preconditioning augments efficacy of human endothelial progenitor cells for therapeutic neovascularization. Lab. Invest. 83, 65-73.

Anandanadesan, R., Gong, Q., Chipitsyna, G., Witkiewicz, A., Yeo, C.J., and Arafat, H.A. (2008). Angiotensin II induces vascular endothelial growth factor in pancreatic cancer cells through an angiotensin II type 1 receptor and ERK1/2 signaling. J. Gastrointest. Surg. 12, 57-66.

Asahara, T., Murohara, T., Sullivan, A., Silver, M., van der Zee, R., Li, T., Witzenbichler, B., Schatteman, G., and Isner, J.M. (1997). Isolation of putative progenitor endothelial cells for angiogenesis. Science 275, 964-967

Asahara, T., Takahashi, T., Masuda, H., Kalka, C., Chen, D. Iwaguro, H., Inai, Y., Silver, M., and Isner, J.M. (1999). VEGF contributes to postnatal neovascularization by mobilizing bone marrow-derived endothelial progenitor cells. EMBO J. 18, 39643972.

Babic, A.M., Kireeva, M.L., Kolesnikova, T.V., and Lau, L.F. (1998). CYR61, a product of a growth factor-inducible immediate early gene, promotes angiogenesis and tumor growth. Proc. Natl. Acad. Sci. USA 95, 6355-6360.

Ceradini, D.J., Kulkarni, A.R., Callaghan, M.J., Tepper, O.M., Bastidas, N., Kleinman, M.E., Capla, J.M., Galiano, R.D., Levine, J.P., and Gurtner, G.C. (2004). Progenitor cell trafficking is regulated by hypoxic gradients through HIF-1 induction of SDF1. Nat. Med. 10, 858-864.

Chen, N., Chen, C.C., and Lau, L.F. (2000). Adhesion of human skin fibroblasts to Cyr61 is mediated through integrin alpha 6beta 1 and cell surface heparan sulfate proteoglycans. J. Biol. Chem. 275, 24953-24961.

Chen, J., Xiao, X., Chen, S., Zhang, C., Chen, J., Yi, D., Shenoy, V., Raizada, M.K., Zhao, B., and Chen, Y. (2013). Angiotensinconverting enzyme 2 priming enhances the function of endothelial progenitor cells and their therapeutic efficacy. Hypertension 61, 681-689.

Clapp, C., Thebault, S., Jeziorski, M.C., and Martinez De La Escalera, G. (2009). Peptide hormone regulation of angiogenesis. Physiol. Rev. 89, 1177-1215.

David, S., Kumpers, P., Lukasz, A., Kielstein, J.T., Haller, H., and Fliser, D. (2009). Circulating angiopoietin-2 in essential hypertension: relation to atherosclerosis, vascular inflammation, and treatment with olmesartan/pravastatin. J. Hypertens. 27, 1641-1647

Dome, B., Timar, J., Dobos, J., Meszaros, L., Raso, E., Paku, S., Kenessey, I., Ostoros, G., Magyar, M., Ladanyi, A., et al. (2006) Identification and clinical significance of circulating endothelial progenitor cells in human non-small cell lung cancer. Cancer Res. 66, 7341-7347.

Fadini, G.P., Losordo, D., and Dimmeler, S. (2012). Critical reevaluation of endothelial progenitor cell phenotypes for therapeutic and diagnostic use. Circ. Res. 110, 624-637.

Fiedler, U., and Augustin, H.G. (2006). Angiopoietins: a link between angiogenesis and inflammation. Trends Immunol. 27, 552-558.

Forte, P., Copland, M., Smith, L.M., Milne, E., Sutherland, J., and Benjamin, N. (1997). Basal nitric oxide synthesis in essential hypertension. Lancet 349, 837-842.

Fu, G.S., Zheng, H., Dai, T., and Huang, H. (2007). Migration of endothelial progenitor cells mediated by stromal cell-derived Factor-1 alpha/CXCR4 via PI3K/Akt/eNOS signal transduction 
pathway. J. Cardiovasc. Pharmacol. 50, 274-280.

Furuya, M., Ishida, J., Inaba, S., Kasuya, Y., Kimura, S., Nemori, R., and Fukamizu, A. (2008). Impaired placental neovascularization in mice with pregnancy-associated hypertension. Lab. Invest. 88 , 416-429.

Genain, C., Bouhnik, J., Tewksbury, D., Corvol, P., and Menard, J. (1984). Characterization of plasma and cerebrospinal fluid human angiotensinogen and des-angiotensin I-angiotensinogen by direct radioimmunoassay. J. Clin. Endocrinol. Metab. 59, 478484.

Giannotti, G., Doerries, C., Mocharla, P.S., Mueller, M.F., Bahlmann, F.H., Horvath, T., Jiang, H., Sorrentino, S.A., Steenken, N., Manes, C., et al. (2010). Impaired endothelial repair capacity of early endothelial progenitor cells in prehypertension: relation to endothelial dysfunction. Hypertension 55, 1389-1397.

Huang, P.L., Huang, Z., Mashimo, H., Bloch, K.D., Moskowitz, M.A., Bevan, J.A., and Fishman, M.C. (1995). Hypertension in mice lacking the gene for endothelial nitric oxide synthase. Nature 377, 239-242.

Hur, J., Yang, H.M., Yoon, C.H., Lee, C.S., Park, K.W., Kim, J.H., Kim, T.Y., Kim, J.Y., Kang, H.J., Chae, I.H., et al. (2007). Identifiation of a novel role of $T$ cells in postnatal vasculogenesis: characterization of endothelial progenitor cell colonies. Circuation 116, 1671-1682.

Igreja, C., Courinha, M., Cachaco, A.S., Pereira, T., Cabecadas, J., da Silva, M.G., and Dias, S. (2007). Characterization and clinical relevance of circulating and biopsy-derived endothelial progenitor cells in lymphoma patients. Haematologica 92, 469477 .

Ishigami, T., Umemura, S., Iwamoto, T., Tamura, K., Hibi, K., Yamaguchi, S., Nyuui, N., Kimura, K., Miyazaki, N., and Ishii, M. (1995). Molecular variant of angiotensinogen gene is associated with coronary atherosclerosis. Circulation 91, 951-954

Jung, S.Y., Choi, J.H., Kwon, S.M., Masuda, H., Asahara, T., and Lee, Y.M. (2012). Decursin inhibits vasculogenesis in early tumor progression by suppression of endothelial progenitor cell differentiation and function. J. Cell. Biochem. 113, 1478-1487.

Kaji, K., Yoshiji, H., Ikenaka, Y., Noguchi, R., Aihara, Y., Shirai, Y., Douhara, A., and Fukui, H. (2012). Possible involvement of angiogenesis in chronic liver diseases: interaction among reninangiotensin-aldosterone system, insulin resistance and oxidative stress. Curr. Med. Chem. 19, 1889-1898.

Kalka, C., Masuda, H., Takahashi, T., Kalka-Moll, W.M., Silver, M., Kearney, M., Li, T., Isner, J.M., and Asahara, T. (2000). Transplantation of ex vivo expanded endothelial progenitor cells for therapeutic neovascularization. Proc. Natl. Acad. Sci. USA 97, 3422-3427.

Kim, H.S., Krege, J.H., Kluckman, K.D., Hagaman, J.R., Hodgin, J.B., Best, C.F., Jennette, J.C., Coffman, T.M., Maeda, N., and Smithies, O. (1995). Genetic control of blood pressure and the angiotensinogen locus. Proc. Natl. Acad. Sci. USA 92, 27352739.

Kim, M.S., Lee, C.S., Hur, J., Cho, H.J., Jun, S.I., Kim, T.Y., Lee, S.W., Suh, J.W., Park, K.W., Lee, H.Y., et al. (2009). Priming with angiopoietin-1 augments the vasculogenic potential of the peripheral blood stem cells mobilized with granulocyte colonystimulating factor through a novel Tie2/Ets-1 pathway. Circuation 120, 2240-2250

Kobori, H., Nangaku, M., Navar, L.G., and Nishiyama, A. (2007). The intrarenal renin-angiotensin system: from physiology to the pathobiology of hypertension and kidney disease. Pharmacol. Rev. 59, 251-287.

Kugathasan, L., Ray, J.B., Deng, Y., Rezaei, E., Dumont, D.J., and Stewart, D.J. (2009). The angiopietin-1-Tie2 pathway prevents rather than promotes pulmonary arterial hypertension in transgenic mice. J. Exp. Med. 206, 2221-2234.

Kwon, S.M., Lee, Y.K., Yokoyama, A., Jung, S.Y., Masuda, $H$., Kawamoto, A., Lee, Y.M., and Asahara, T. (2011). Differential activity of bone marrow hematopoietic stem cell subpopulations for EPC development and ischemic neovascularization. J. Mol. Cell. Cardiol. 51, 308-317.

Lee, S.P., Youn, S.W., Cho, H.J., Li, L., Kim, T.Y., Yook, H.S., Chung, J.W., Hur, J., Yoon, C.H., Park, K.W., et al. (2006). Integrinlinked kinase, a hypoxia-responsive molecule, controls postnatal vasculogenesis by recruitment of endothelial progenitor cells to ischemic tissue. Circulation 114, 150-159.
Lee, S.W., Kim, W.J., Jun, H.O., Choi, Y.K., and Kim, K.W. (2009). Angiopoietin-1 reduces vascular endothelial growth factorinduced brain endothelial permeability via upregulation of ZO-2. Int. J. Mol. Med. 23, 279-284.

Li, B., Sharpe, E.E., Maupin, A.B., Teleron, A.A., Pyle, A.L., Carmeliet, P., and Young, P.P. (2006). VEGF and PIGF promote adult vasculogenesis by enhancing EPC recruitment and vessel formation at the site of tumor neovascularization. FASEB J. 20, 1495-1497.

Mandriota, S.J., and Pepper, M.S. (1998). Regulation of angiopoietin-2 mRNA levels in bovine microvascular endothelial cells by cytokines and hypoxia. Circ. Res. 83, 852-859.

Marsboom, G., Pokreisz, P., Gheysens, O., Vermeersch, P., Gillijns, H., Pellens, M., Liu, X., Collen, D., and Janssens, S. (2008) Sustained endothelial progenitor cell dysfunction after chronic hypoxia-induced pulmonary hypertension. Stem Cells 26, 10171026

Masuda, H., Alev, C., Akimaru, H., Ito, R., Shizuno, T., Kobori, M., Horii, M., Ishihara, T., Isobe, K., Isozaki, M., et al. (2011). Methodological development of a clonogenic assay to determine endothelial progenitor cell potential. Circ. Res. 109, 20-37.

Mendez, G.P., Klock, C., and Nose, V. (2011). Juxtaglomerular cell tumor of the kidney: case report and differential diagnosis with emphasis on pathologic and cytopathologic features. Int. J. Surg Pathol. 19, 93-98.

Murohara, T., Asahara, T., Silver, M., Bauters, C., Masuda, H., Kalka C., Kearney, M., Chen, D., Symes, J.F., Fishman, M.C., et al. (1998). Nitric oxide synthase modulates angiogenesis in response to tissue ischemia. J. Clin. Invest. 101, 2567-2578.

Naik, R.P., Jin, D., Chuang, E., Gold, E.G., Tousimis, E.A., Moore, A.L., Christos, P.J., de Dalmas, T., Donovan, D., Rafii, S., et al. (2008). Circulating endothelial progenitor cells correlate to stage in patients with invasive breast cancer. Breast Cancer Res. Treat 107, 133-138.

Obi, S., Yamamoto, K., Shimizu, N., Kumagaya, S., Masumura, T. Sokabe, T., Asahara, T., and Ando, J. (2009). Fluid shear stress induces arterial differentiation of endothelial progenitor cells. J. Appl. Physiol. 106, 203-211.

Pereira, R.M., Michalkiewicz, E., Sandrini, F., Figueiredo, B.C., Pianovski, M., Franca, S.N., Boguszewski, M.C., Costa, O., Cat I., Lacerda Filho, L., et al. (2004). [Childhood adrenocortical tumors]. Arq. Bras. Endocrinol. Metabol. 48, 651-658.

Rentzsch, B., Todiras, M., Iliescu, R., Popova, E., Campos, L.A Oliveira, M.L., Baltatu, O.C., Santos, R.A., and Bader, M. (2008) Transgenic angiotensin-converting enzyme 2 overexpression in vessels of SHRSP rats reduces blood pressure and improves endothelial function. Hypertension 52, 967-973.

Robinson, E.S., Khankin, E.V., Karumanchi, S.A., and Humphreys B.D. (2010). Hypertension induced by vascular endothelial growth factor signaling pathway inhibition: mechanisms and potential use as a biomarker. Semin. Nephrol. 30, 591-601.

Roks, A.J., Rodgers, K., and Walther, T. (2011). Effects of the renin angiotensin system on vasculogenesis-related progenitor cells. Curr. Opin. Pharmacol. 11, 162-174.

Roncalli, J., Renault, M.A., Tongers, J., Misener, S., Thorne, T., Kamide, C., Jujo, K., Tanaka, T., li, M., Klyachko, E., et al. (2011) Sonic hedgehog-induced functional recovery after myocardia infarction is enhanced by AMD3100-mediated progenitor-cell mobilization. J. Am. Coll. Cardiol. 57, 2444-2452.

Shweiki, D., Itin, A., Soffer, D., and Keshet, E. (1992). Vascular endothelial growth factor induced by hypoxia may mediate hypoxia-initiated angiogenesis. Nature 359, 843-845.

Silvestre, J.S., Tamarat, R., Senbonmatsu, T., Icchiki, T., Ebrahimian, T., Iglarz, M., Besnard, S., Duriez, M., Inagami, T., and Levy, B.I (2002). Antiangiogenic effect of angiotensin II type 2 receptor in ischemia-induced angiogenesis in mice hindlimb. Circ. Res. 90, 1072-1079.

Smadja, D.M., Bieche, I., Helley, D., Laurendeau, I., Simonin, G., Muller, L., Aiach, M., and Gaussem, P. (2007). Increased VEGFR2 expression during human late endothelial progenitor cells expansion enhances in vitro angiogenesis with upregulation of integrin alpha(6). J. Cell. Mol. Med. 11, 1149-1161.

Tanimoto, K., Sugiyama, F., Goto, Y., Ishida, J., Takimoto, E., Yagami, K., Fukamizu, A., and Murakami, K. (1994). Angiotensinogen-deficient mice with hypotension. J. Biol. Chem. 269, 31334-31337. 
Urbich, C., and Dimmeler, S. (2004). Endothelial progenitor cells: characterization and role in vascular biology. Circ. Res. 95, 343353.

Vallance, P., Collier, J., and Moncada, S. (1989). Effects of endothelium-derived nitric oxide on peripheral arteriolar tone in man. Lancet 2, 997-1000.

Ward, K., Hata, A., Jeunemaitre, X., Helin, C., Nelson, L., Namikawa, C., Farrington, P.F., Ogasawara, M., Suzumori, K., Tomoda, S., et al. (1993). A molecular variant of angiotensinogen associated with preeclampsia. Nat. Genet. 4, 59-61.

Wu, H.H., Ivkovic, S., Murray, R.C., Jaramillo, S., Lyons, K.M., Johnson, J.E., and Calof, A.L. (2003). Autoregulation of neurogenesis by GDF11. Neuron 37, 197-207.

Yang, H.Y., Bian, Y.F., Zhang, H.P., Gao, F., Xiao, C.S., Liang, B., Li, J., Zhang, N.N., and Yang, Z.M. (2012). Angiotensin-(1-7) treatment ameliorates angiotensin II-induced apoptosis of human umbilical vein endothelial cells. Clin. Exp. Pharmacol. Physiol. 39, 1004-1010.

Yoon, J., Choi, S.C., Park, C.Y., Choi, J.H., Kim, Y.I., Shim, W.J., and Lim, D.S. (2008). Bone marrow-derived side population cells are capable of functional cardiomyogenic differentiation. Mol. Cells 25, 216-223.

Youn, S.W., Lee, S.W., Lee, J., Jeong, H.K., Suh, J.W., Yoon, C.H., Kang, H.J., Kim, H.Z., Koh, G.Y., Oh, B.H., et al. (2011). COMPAng1 stimulates HIF-1alpha-mediated SDF-1 overexpression and recovers ischemic injury through BM-derived progenitor cell recruitment. Blood 117, 4376-4386.

Ziaja, J., Cholewa, K., Mazurek, U., and Cierpka, L. (2008). [Molecular basics of aldosterone and cortisol synthesis in normal adrenals and adrenocortical adenomas]. Endokrynol. Pol. 59, 330339. 